\title{
EDUCAÇÃO INTEGRAL NO SISTEMA SOCIOEDUCATIVO: O CURRÍCULO COMO REDES DE SIGNIFICAÇÕES DISCURSIVAS
}

Rafael Ferreira de Souza Honorato ${ }^{1}$ Ângela Cristina Alves Albino ${ }^{2}$ Ana Cláudia da Silva Rodrigues ${ }^{3}$

\section{INTRODUÇÃO}

A organização curricular da Educação Integral para Jovens em Cumprimento de Medidas Socioeducativas em Privação de Liberdade constitui o objeto de estudo deste texto. O trabalho parte da compreensão do currículo como redes de significação discursivas e pretende analisar como o processo de mobilidade, hibridismo e (re)contextualizações tece relações de poder/saber e gera currículos em constantes processos de significação.

Neste texto resolvemos assumir o currículo como discurso, que está permeado por relações de poder, presentes no tecido das redes de significação discursiva que o constituem. Essa rede, todavia, está em constante deslocamento, incluindo e excluindo discursos, demandas, pautas. Esses deslocamentos provocam uma polissemia de significações da prática social e cultural nele produzida. Essa característica produz uma dinâmica complexa mediada pelo poder que se estabelece a partir de negociações, o que nos coloca cada vez mais distante de processos dialéticos (opressor e oprimido) e de possibilidades de um pretenso consenso como resultado de práticas que subvertem o processo de negociação (LOPES, 2006; PEREIRA, 2009, 2010; PEREIRA; ALBINO; MAIA, 2012).

O processo de mobilidade dessas políticas curriculares, como aponta Ball (2014), revela que as ideias não se movimentam no vácuo, mas a partir de divulgações nos microespaços. Assim, defendemos que existe um processo de (re)contextualização, fruto de (re)interpretações de políticas que foram mobilizadas de outros países e/ou contextos diferentes. Tais processos geram híbridos curriculares discursivos, que tratam da mistura de concepções e (re)contextualização de propostas

\footnotetext{
${ }^{1}$ Doutorando na linha de pesquisa Políticas Educacionais, Mestre na linha de pesquisa Políticas Educacionais, ambos pelo Programa de Pós-Graduação em Educação da Universidade Federal da Paraíba, João Pessoa, Paraíba, Brasil, Email: rafaelhono@gmail.com, ORCID: https://orcid.org/0000-0002-6196-0211

2 Doutora, Professora adjunta da Universidade Federal da Paraíba, E-mail: angela.educ@gmail.com, ORCID: https://orcid.org/0000-0003-2452-1444

${ }^{3}$ Doutora, Professora do Departamento de Fundamentação da Educação do Centro de Educação da Universidade Federal da Paraíba, E-mail: anaclaudia@ce.ufpb.br, ORCID: https://orcid.org/0000-0001-6621-1861
} 
curriculares, possível “[...] pela negociação de sentidos nos diferentes momentos da produção de todos esses textos e discursos da reforma" (LOPES, 2006, p. 40).

Pode-se dizer, de imediato, que a Educação Integral e as dimensões que a compõem: currículo, gestão e avaliação são temas de discussão constante, tanto nas universidades, quanto nas escolas. Por trás disso, há o pressuposto de que a Educação Integral é sinônimo de Educação de Qualidade. Por isso, há uma tentativa de qualificar o ensino a partir da ampliação da jornada escolar, da investidura nos processos de formação das várias dimensões dos sujeitos, por sua vez, dos conhecimentos legitimados como necessários a essa formação do "sujeito integral".

Tal perspectiva suscitou estudos sobre o currículo como elemento de discussão importante nos estudos sobre Educação Integral, considerando o movimento de globalização, que trouxe a mobilidade das políticas educacionais, através das orientações de organismos multilaterais, como a Organização de Cooperação e de Desenvolvimento Econômico (OCDE) e o Banco Mundial (BM), com vistas à descentralização da gestão pública. Nesta direção, também começaram a compor a rede de significação discursiva instituições como o Todos pela Educação, considerada como instituiçãochave, que vem exercendo forte influência na elaboração de currículos, impondo uma mudança paradigmática no fazer curricular, que fortalece a formação de mão de obra para o mercado, a ideia de precarização do serviço público em detrimento do privado, a marginalização do conhecimento das classes populares, a inserção do modelo de mercado na gestão escolar, a competitividade como forma de manutenção do financiamento.

Destarte, a Educação Integral, não só pressupõe uma mudança nas concepções e no paradigma, quanto nas práticas tradicionais, que ainda são presentes na educação. Mas, também, ela pode ser um espaço fértil para exercer tais práticas, quando através do currículo se estabelecem padrões de culturas, etnias, religiões, sexo, gênero, que pautam as diferenças. É necessário considerar que, no Brasil, esta sempre esteve voltada para o atendimento de crianças de classes populares influência da realidade internacional. Só com essa afirmação podemos pressupor que estão incutidas no pensamento curricular da Educação Integral formas de conceber os adolescentes e jovens.

Por esse motivo objetivamos analisar as redes de significações discursivas presentes na organização curricular da Educação Integral para Jovens em Cumprimento de Medidas Socioeducativas em Privação de Liberdade do estado da Paraíba, como também, provocar diálogos, reflexões, produções que preencham, sempre provisoriamente, a lacuna que encontramos no mapeamento realizado no catálogo de teses e dissertações da Coordenação de Aperfeiçoamento de Pessoal de Nível Superior (CAPES). 
Destacamos que nos deparamos com a ausência de estudos sobre educação na socioeducação, principalmente quanto a programas e políticas de currículo (de tempo) integral, em espaços e tempos iguais ou similares aos do cumprimento de medidas socioeducativas da Paraíba. O que nos faz considerar ainda que as políticas de currículo para a educação para adolescentes e jovens em privação de liberdade não têm sido pauta nos espaços de discussão sobre educação no Brasil.

A análise que desenvolvemos segue a abordagem qualitativa, através do exame de documentos e de 02 (dois) entrevistas semiestruturadas oriundas da pesquisa de campo, com os elaboradores da política. Compõe o léxico do estudo o texto da política curricular, Decreto $\mathrm{n}^{\mathrm{o}} 37.505$, de 18 de julho de 2017, que criou o Programa de Educação Cidadã Integral para o Atendimento de Jovens em Cumprimento de Medidas Socioeducativas - Janela para o Futuro com objetivo de "[...] ofertar Educação Básica aos jovens em cumprimento de Medidas Socioeducativas, promovendo a formação de cidadãos autônomos, solidários, competentes que possam construir/resgatar sua cidadania e atuar produtivamente na sociedade e no mercado de trabalho" (PARAÍBA, 2017, p. 12)

O programa possui proposta pedagógica própria, bem como modelo curricular e de gestão administrativa específica para o público da socioeducação. Também, foram analisados o Plano Estadual de Atendimento Socioeducativo da Paraíba (2015 - 2024) e a Resolução CNE/CEB n 3, de 13 de maio de 2016, que define Diretrizes Nacionais para o atendimento escolar de adolescentes e jovens em cumprimento de medidas socioeducativas. O programa é uma política intersetorial que articula três instituições: a Secretaria de Estado da Educação e Ciência e Tecnologia (SEECT), Fundação de Desenvolvimento da Criança e do Adolescente Alice de Almeida (FUNDAC) e a Secretaria de Estado do Desenvolvimento Humano (SEDH).

Dividimos o texto em três momentos que podem nos ajudar a compreender a rede de significação discursiva, mas também as regras que norteiam as práticas: o primeiro tópico irá tratar das nossas lentes de análise, o segundo apresenta o debate político em torno da política curricular em tela e o terceiro analisa o processo de recontextualização por hibridismo que a política passa para ser mobilizada para socioeducação, constituindo-a como um híbrido discursivo.

\section{O CURRÍCULO COMO REDES DE SIGNIFICAÇÕES DISCURSIVAS: LENTES PARA ANÁLISES}

O primeiro exercício que realizamos, neste texto, pretende dar continuidade aos estudos de Pereira (2009a, 2009b, 2010), Pereira, Albino e Maia (2012), Maia (2014) e Macedo Neto (2014, 2015), sobre o currículo como redes de significações discursivas, perspectiva epistemológica 
desenvolvida a partir da Teoria do Discurso - TD (LACLAU, 2011, 2013; LACLAU; MOUFEE, 2015). Neste sentido, destacamos as potencialidades e contribuições desta perspectiva e ampliamos a partir dos estudos de Redes Políticas (BALL, 2012; BALL; JUNEMANN, 2012), dando nossa contribuição ao campo das pesquisas sobre currículo e políticas curriculares.

Os estudos da Teoria do Discurso (LACLAU, 2011, 2013; LACLAU; MOUFFE, 2015) compreendem que o discurso é um elemento constitutivo primário da realidade, ou seja, o discurso se constitui a partir de uma complexa rede de elementos construídos socialmente que geram significados. Nessa perspectiva, o Grupo de Estudos e Pesquisas em Políticas Curriculares (GEPPC) vem, desde 2009, empregando esforços para desenvolver ferramentas de análise para as pesquisas em políticas curriculares, que busquem afastar-se do modelo de sociedade compreendido a partir de uma totalidade fundante com processos parciais (leis internas ou um princípio subjacente) considerando que

O discurso constitui o território primário da construção da objetividade enquanto tal. Por discurso, como tentei esclarecer várias vezes, não tenho em mente algo que é essencialmente relativo às áreas da fala e da escrita, mas quaisquer conjuntos de elementos nos quais as relações desempenham um papel constitutivo (LACLAU, 2013, p. 116).

Para Laclau (2013) a linguagem enquanto retórica ou texto é constituidora da realidade. Todavia, ela está dentro de um discurso que a torna possível. Assim, os elementos representam diferenças sociais que não estão articuladas discursivamente, por não terem demandas comuns entre as presentes no contexto social. Então, os elementos que existem fora do discurso, a que se refere a citação, não possuem significação anterior, pois essas se originam na relação que os constituem, tornando "relação" e "objetividade" sinônimos.

Tais afirmações de Laclau (2013) e as articulações com os estudos de Lopes (2006), Lopes, Oliveira, A. e Oliveira, G. (2018), Lopes, Dias e Abreu (2012), Macedo (2014, 2016, 2017, 2018) nos instigaram a pensar o currículo como discurso, ou seja, complexo, construído através de uma pluralidade de centros, que não está externo ao discurso; por consequência, é um elemento político, moldado pelos antagonismos próprios da prática social, que temporariamente, através da hegemonia, torna-se estável, embora contingente, sendo este “[...] uma totalidade relacional de significantes que limitam a significação das práticas [...]” (LACLAU, 2011, p. 9).

O currículo enquanto discurso não está fora da lógica da diferença. Por isso, este é constituído a partir de uma polissemia de significantes resultantes de uma disputa entre projetos antagônicos, em que o significado resultante definirá as ações políticas-pedagógicas consideradas como válidas. Nesses termos, o currículo se estabelece numa luta entre projetos do social, que visam estabelecer 
limites às práticas curriculares, tentando articular ao seu entorno o maior número de demandas para agregar apoiadores e aliados. Ou seja, o currículo é representativo de uma série de demandas particulares.

$\mathrm{Na}$ intenção de agregar o maior número de demandas possíveis o discurso assume uma elasticidade, o que dá a impressão de uma heterogeneidade de demandas. Tal aspecto amplia o discurso através de uma rede de equivalência alimentando um sentimento de representação. É nesse processo que podem ser constituídas as formações discursivas, quando os discursos são articulados hegemonicamente. "[...] Entender uma formação discursiva significa entender um processo hegemônico: como são definidos os termos do debate político, quais agendas e ações são priorizadas, que instituições, diretrizes e normas são criadas" (LACLAU, 2011, p. 9-10).

Assim, seria fulcral pensar que as políticas curriculares só se tornam hegemônicas, por serem constituídas como redes de significações discursivas, que através da lógica da equivalência, articularam discursos, em torno das demandas heterogêneas comuns que representam seus apoiadores e aliados. Por essas redes escoam sentidos de currículo que visam estabelecer controle sobre os sentidos para o currículo. Essa tentativa de controle se dá através de artefatos como texto, vídeos e manuais que visam explicar os sentidos da política hegemônica em detrimento dos demais discursos que disputam.

Porém, deslocamentos não são impossíveis. Eles acontecem quando determinados discursos sentem dificuldades de dar respostas às contestações que emergem da prática social, evidenciando o seu caráter contingente, o que estabelece uma crise de sentidos e enfraquece a equivalência. É importante enfatizar que, numa formação discursiva, a transformação de elementos em momentos jamais é completa, o que sugere uma tensão permanente e nunca resolvida, de maneira que as diferenças articuladas permanecem num espaço intermediário entre momentos e elementos.

Nesses termos, o sentido de algo não é plenamente fixado, este é sempre determinado por suas relações com discursos exteriores que vêm a deformá-lo, impedindo-o de se tornar totalmente fechado. As identidades são puramente relacionais, de maneira que sua constituição plena é impossível (LACLAU; MOUFFE, 2015).

Desta forma, passamos a operar com a ideia de política de currículo como redes de significação discursivas, que, embora fruto da contingência e dos antagonismos, estabelecem uma certa estabilidade. Embora precárias, constroem um conjunto de regras para os currículos, estancando as fissuras com a imposição dos pontos nodais, que são os pontos de articulação das demandas, ou, como são chamados por Laclau (2013), significantes vazios. 
Todavia, é necessário considerar que as redes de significações discursivas, enquanto estrutura que serve de alicerce para hegemonização do discurso sobre currículo, não tornam os discursos que se articulam em rede homogêneos, muito menos destroem as diferenças que os compõem. Mas, tratase de uma necessidade para enfrentar um adversário comum. Isso possibilita uma hegemonia temporária, para após retornarem às suas diferenças, que no momento da articulação estão latentes, possibilitando uma disputa entre os discursos no interior da própria rede. Como nos lembra Laclau e Mouffe (2015), o processo de articulação, deslocamento e nova articulação é contínuo.

Nesse movimento de (re)criação de uma perspectiva teórica para as políticas de currículo, os estudos de Ball (2014) fortaleceram nosso entendimento de que os discursos sobre o currículo estão sendo estabelecidos em rede, esta última passando a funcionar como tecido conectivo por onde os discursos circulam e a mobilidade acontece, sendo recontextualizadas por hibridismo nos espaços das micropolíticas. E essas redes estão conseguindo hegemonizar discursos sobre currículo, mesmo que precariamente, em um processo de inclusão e exclusão de possibilidades, figurados pela lógica da diferença e equivalência, a partir dos interesses distintos, por encontrar demandas particulares nas práticas sociais que são ontologicamente políticas.

Ao dizer que a “[...] política educacional está sendo feita em novas localidades, em diferentes parâmetros, por novos atores e associações" (BALL, 2014, p. 27) e que essas novas localidades afetam a maneira como os pesquisadores lidam com a pesquisa, devendo adaptar-se a esses deslocamentos, o supracitado autor nos instigou a trazer as redes para as análises curriculares, ampliando o entendimento do currículo como discurso para redes de significação discursiva. Percebemos que através dessas redes é possível recuperar os múltiplos fluxos entre os diferentes agentes políticos no momento da decisão (BALL, 2012; BALL; JUNEMANN, 2012).

Ball e Junemann (2012, p. 55) definem redes como "comunidades políticas" descentradas, articuladas em busca de soluções para os problemas sociais comuns. Para Laclau (2013) isso seria os discursos tentando dar conta do social atribuindo sentidos às suas demandas. É a partir dessas redes que os sujeitos políticos se constituem, também de forma contingencial, pela articulação das diversas demandas, como na Teoria do Discurso (LACLAU, 2013).

Estudos de teses, dissertações realizadas ou em andamento, bem como outros manuscritos têm demonstrado uma diversidade de relações que se estabelecem nas redes, bem como uma movimentação de atores que diferem de contexto para contexto, ou até mesmo com a mudança dos interesses de cada um que compõe a rede. A rede se mantém como um discurso hegemônico, mas contingente, em contínua mudança, o que leva Ball (2012) a considerar que sua pouca clareza é um 
limite para a utilização da noção. Assim, as redes são caracterizadas por uma multiplicidade de demandas e agentes políticos que assumem a forma de equivalência.

A política de currículo como redes de significações discursivas é a soma das dimensões da Teoria do Discurso e das Redes de Política, o que viabiliza uma análise das hegemonias e das formas como se constroem em suas relações complexas plurilaterais e não predeterminadas entre uma multiplicidade de discursos. Nessas condições teórico-metodológicas seria possível a leitura dos fluxos de poder e regimes de verdade que constituem os próprios contextos das políticas curriculares a partir da velocidade com que as articulações e as contingências das hegemonias acontecem.

Essa perspectiva que defendemos também possibilita compreendermos que o currículo produz pontos nodais diversos, ao longo de sua trajetória através da rede política, levando em consideração o tempo e lugar, e, ao aglutinar, vão fixando-os e deslocando continuamente. Nesse processo de (re)significação o currículo assume o caráter de significante vazio. De um lado, ele incorpora os discursos que perpassam na sociedade produzidos através da fixação e dos deslocamentos de modelos de currículos que com seus particularismos se diversificam em modelos curriculares centrados em temas como pluralidade cultural, direitos humanos, ético, multicultural, emancipador, performático, interdisciplinar, multidisciplinar, integrado. De outro, afirmamos que os diferentes discursos que perpassam a sociedade (contexto), através das agências políticas, criam e normatizam os textos (Políticas educacionais, leis, resoluções, regimentos, diretrizes curriculares) desses discursos que os grupos sociais ao desenvolverem suas práticas (ações) através de suas agências civis representativas tentam legitimar e reconhecer as suas diversas lutas sociais (PEREIRA, 2009).

Essas formações discursivas vão ganhando legitimidade à medida que ganham materialidade na sala de aula e demais espaços educativos e sociais, através da performatividade das pessoas, imagens e palavras. Entretanto, os particularismos são fluidos, abertos, contingentes, ambivalentes, plurais e resultam da tensão negociada no jogo das diferenças (PEREIRA, 2009).

Nos próximos tópicos apresentamos as dimensões do debate político buscando a segunda face desse texto que foi compreender as articulações que hegemonizaram posições popularizadas, de diferentes sujeitos, sobre currículo da educação integral para as unidades socioeducativas de privação de liberdade.

\section{TERMOS DO DEBATE POLÍTICO QUE ENUNCIARAM AS DEMANDAS PARA O CURRÍCULO}

Neste tópico analisamos as demandas estabelecidas para a política de currículo do sistema socioeducativo, ou seja, começamos nossa caminhada para compreender a formação discursiva de 
significação para entender o processo hegemônico, o que consistiu em mapearmos, na rede discursi va, o debate político, as agendas e ações priorizadas.

A qualidade da educação se configura, aqui, como uma das demandas, ou pontos nodais, como chamado por Laclau (2013) e Macedo (2014), do discurso da política curricular que desencadeou articulações discursivas, entre elementos/momentos (que são posições diferentes num determinado discurso através das articulações que formam as redes, ou o discurso hegemônico possibilitando uma sustentação, precária e antagônica). Assim, ocorreu a hegemonização do discurso que elucidou a necessidade de uma política curricular para a educação integral no sistema socioeducativo.

Mas, a partir da Teoria do Discurso é compreensível que, numa rede, elementos/momentos (pontos nodais) estejam articulados com outros discursos, sendo os pontos nodais suas demandas comuns. Assim, nosso percurso tem como objetivo dar visibilidade a esses outros discursos que compõem a rede discursiva, que estão articulados através de pontos nodais com as demandas da política curricular para a socioeducação.

É pertinente considerar que a organização curricular investigada é proposta em meio a um discurso político, explicitado pelo entrevistado 2, na transcrição abaixo,

[...] a socioeducação na verdade, tem uma carência, claro, muito maior... Você imagina o que é um adolescente cheio de hormônio, cheio de desesperança né, cheio de ódio, o cara trancado numa, numa cela? É um horror, é um negócio, que, sabe, então isso nunca pode dar certo [...] (ENTREVISTADO 2, 2019).

O discurso de que é necessário uma política curricular que dê conta do ócio toma centralidade no debate político, estabelecendo novas agendas para a socioeducação. Mas, esse discurso passa a ocupar uma centralidade nas demandas, a partir da rebelião que aconteceu em uma das unidades, em junho de 2017, deixando sete mortos.

No desencadeamento dos fatos, o entrevistado 2 (2019), destacou a necessidade de uma intervenção, “[ ...] coloquei a atual secretária de desenvolvimento, [...] lá dentro sabe, disse olhe, - não como diretor, mas, como uma das diretoras, carta branca, eu quero ensino integral e profissionalizante[...]". Daí começaram a ser desencadeadas as demandas da política curricular que estamos investigando.

Uma das primeiras demandas priorizadas para a Política Curricular, já citadas na fala anterior do entrevistado 2, diz respeito à Educação Integral e outra se refere à profissionalização dos adolescentes e jovens. Assim, a política de currículo integral para a socioeducação deveria, através do componente curricular, Projeto de Vida, eixo principal das Escolas Cidadãs Integrais, deveria 
articular a profissionalização de forma que fosse além de um projeto de carreira profissional, mas um processo de reflexão sobre o "ser e querer ser" (PARAÍBA, 2017, p. 11).

[...] a proposta pedagógica tem que casar também com a sobrevivência, daqui a pouquinho o cara sai, tem gente que não quer entrar pra universidade, tem gente que quer, enfim, que precisa ganhar a vida então (a escolha da profissão) é algo fundamental, né?, pois bem, na socioeducação mais ainda, então nós começamos isso [...] (ENTREVISTADO 2. 2019).

As entrevistas realizadas nos deram a possibilidade de entendermos a vontade que existiu em estabelecer um currículo a partir de conhecimentos predeterminados pelas necessidades do mercado de trabalho, de forma a contribuir com um projeto de transformação social e de formação de sujeitos. Por isso, é possível compreender como a Educação Integral se tornou um ponto nodal, na rede de significação discursiva. Isso fica mais forte ainda com as afirmações que o entrevistado 2 (2019) fez ao dizer que

[...] não há nenhum estudo que diga que a escola integral é pior do que a escola regular, há todos os indicadores que dizem que a escola integral tá sendo melhor do que, melhor na socialização do estudante, melhor na alimentação, melhor no protagonismo juvenil, melhor na relação com as famílias [...].

A Educação Integral, como um dos discursos que se articularam à rede de significações discursivas, elucidou outras demandas pertinentes ao sistema socioeducativo.

[...] essa coisa da socialização a ideia central é educação integral e com os cursos profissionalizantes, ninguém é obrigado a ir, você tem um pessoal que não vai querer... é um pessoal que tá num estágio diferente da grande maioria, mas uns inclusive trabalham para que outros não possam nem ir, né? [...] naquelas relações lá dentro isso tem muito. Porém, você tem uma mudança muito forte porque imagina você tá dentro de uma cela, e aí com cultura, com muita arte, né? Enfim que faz bem ao espírito, né? E também com o curso profissionalizante [...] (ENTREVISTADO 2, 2019).

Essa fala apresenta outra demanda para a política de currículo de Educação Integral da socioeducação. $\mathrm{O}$ ato infracional, que esses adolescentes e jovens cometeram, foi o dispositivo que conduziu ao cumprimento da medida socioeducativa e o principal objetivo é evitar que eles voltem a cometer tais atos. Esse objetivo é um dos pontos nodais que também se tornou articulador na rede. Segundo a entrevistada 1 (2019), foi solicitado pelo governador que o secretário de segurança pública fizesse "um mapa com os locais de maior índice de violência, que o objetivo era exatamente colocar as escolas nessas localidades, para ver exatamente, de forma mais rápida os resultados”. Assim, a política curricular teve que ser estruturada de forma a dar resultados rápidos quanto à redução da violência nos espaços sociais nos quais estavam inseridas as escolas. 
Os dois entrevistados apresentaram informações quanto às pesquisas realizadas para verificar os impactos dessas escolas nos índices de violência das regiões onde foram implantadas as escolas integrais e segundo eles os índices reduziram, chegando a 70\% de redução em localidades em que as escolas estavam instaladas há mais tempo.

[...] ele demonstrou lá, fez uma mancha entre algumas regiões ou algumas comunidades onde escola integral versus homicídio de jovens e a queda é muito maior do que a queda que tem na Paraíba que é uma queda também bastante consistente né, apesar dessa propaganda contra, mas é a queda mais consistente no Brasil ao longo de oito anos é aqui na Paraíba e isso se expressa onde tem escola integral, e por que isso? Por razão óbvia, se ao invés de deixar o cara à disposição da criminalidade por não ter o que fazer, por não acreditar em nada, por não ter caminho; se eu consigo dar alguma expectativa de vida futura é evidente que essa pessoa vai ter outros interesses além daquele outro que tá lá não é? A educação integral se, se a proposta de educação integral a proposta de educação integral eu não vou nem entrar no mérito do conteúdo tal [...] (ENTREVISTADO 2, 2019).

Esse discurso, um dos pontos nodais, estabeleceu pontos de equivalência focados na centralidade do sujeito, com identidades fixas, através da conjuntura de um projeto curricular que tem por propósito formar uma dada identidade no aluno ou operar com uma identidade docente préestabelecida.

Ao reconhecermos o descentramento do discurso da política curricular e a impossibilidade de uma contextualização radical, assim como Lopes (2015b, p. 447), podemos questionar essa proposta de currículo comum, para qualquer nível e/ou modalidade que vise "construir um fundamento, um padrão, uma base curricular, um conjunto de conteúdos básicos ou mesmo um conjunto de critérios consensuais para definir de uma vez por todas uma identidade para o currículo da educação básica" para os adolescentes e jovens em cumprimento de medida socioeducativa na Paraíba. Com base em Laclau (1990), ainda defendemos que há múltiplas demandas contextuais, contingentes, produzindo sentidos para as políticas. "Há equivalências entre demandas frente a um exterior representado como ameaça ao atendimento dessas mesmas demandas" (LOPES, 2015b, p. 448).

\section{MOBILIDADE, (RE)CONTEXTUALIZAÇÃO E HIBRIDISMOS DA POLÍTICA CURRICULAR}

O terceiro exercício consiste em compreender os regimes de verdade estabelecidos por instituições e as diretrizes que elas criam. Aqui estamos trazendo para as análises categorias dos estudos de Ball (1994, 2014) e Bowe, Ball e Gold (1992), bem como contribuições dos estudos de Macedo e Lopes (2006) para o entendimento dos hibridismos na política investigada. 
Ao trazer os estudos de Ball (1994, p. 120), fazemos o esforço de compreender as políticas de currículo como discursos que não "se movem no vácuo, mas como criações sociais e políticas que são recontadas em microespaços de políticas". Assim, não tratamos esses discursos como criações que partiram do zero, mas que buscam inspirações em outros lugares, tempos, espaços em busca de darem conta de demandas sociais atuais, que não necessariamente são novos.

Esse pensamento é pertinente, uma vez, que a política curricular para o sistema socioeducativo mobilizou o modelo curricular das demais escolas de Educação Integral da Rede Pública do Estado da Paraíba, no que concerne ao modelo pedagógico, princípios, gestão escolar e o próprio currículo, centrando-se no protagonismo juvenil e no projeto de vida com pilares para a formação dos socioeducandos, entendendo que era necessária a ampliação da jornada para nove horas. Assim, a escola que atende na modalidade de Educação de Jovens e Adultos passou a ser integral em todos os níveis de ensino, ou seja, atende das séries iniciais do Ensino Fundamental até o Ensino Médio.

Salientamos que

o que faz com que articulações sempre contingentes se apresentem como um pertencimento universal (Laclau, 2012) é sua capacidade de suturar o social entendido como estrutura deslocada. Os discursos hegemônicos apresentam-se, assim, como um princípio reorganizador do sistema deslocado, permitindo que as crises de significação se tornem intelegíveis (MACEDO, 2014, p. 1536).

Neste sentido, nas Diretrizes das Escolas Cidadãs Integrais Socioeducativas, adaptações foram necessárias para adequar a política curricular das Escolas Cidadãs Integrais do meio aberto, para a socioeducação. Assim, ficou enquanto componente integrador o Projeto de Vida, que se pode dizer que é o elemento inovador da proposta. Para o entrevistado 2 (2019), o que mais chamou a atenção na proposta foi o Projeto de Vida: “[...] eu acho que, que é essencial uma proposta pedagógica inclusive, uma proposta política do ensino integral, é as pessoas quererem ir pra algum canto, não interessa qual seja, interessa que a pessoa quer [...]”. Outro princípio é o protagonismo juvenil, que considera que o estudante é parte da solução e não foco do problema (ICE, 2016). Destacamos que as diretrizes pontuam que na socioeducação o exercício do protagonismo deve envolver não só os professores, mas toda a comunidade da unidade, para "[...] despertar valores, perspectivas e ressignificação das vidas dos jovens e suas relações sociais [...]” (PARAÍBA, 2017, p. 12).

Essa fixação só é possível, segundo Laclau e Mouffe (2015), devido à sobredeterminação que é produzida pelo fechamento contingente do deslocamento por meio de um ponto nodal, que é definido significante vazio. A partir desse momento, a lógica da diferença que constitui a estrutura é transversalizada pela lógica da equivalência, e ambas guardam entre si uma relação de indecidibilidade. 
Com esse pensamento esclarecemos os motivos que levaram as Escolas Cidadãs Integrais da Rede em meio aberto a se tornarem modelo, uma vez que ela dava resposta ao significante vazio da socioeducação que é a ressocialização dos jovens.

Assim, a proposta curricular foi organizada e conta com ações de integração e acompanhamento do estudante, a saber: acolhimento, tutoria, contrato e convivência e salas temáticas. Mas, os princípios passaram por adaptações na execução para não comprometerem a segurança e integridade física, psíquica e moral dos adolescentes e jovens, colocando-os em situação de risco. Desta forma, o acolhimento é feito pela equipe de professores e não pelos jovens, como ocorre nas escolas em meio aberto. A tutoria, serve como instrumento para avaliação semestral dos adolescentes e jovens, enviada às varas para reavaliação da medida socioeducativa. O contrato de convivência serve como acordos que possibilitam a execução das aulas, evitando conflitos entre eles. As salas temáticas são utilizadas como espaços orientadores que delimitam onde os alunos devem estar para assistir aulas de acordo com as áreas de conhecimento. Porém, são organizadas, mas quem troca de sala são os professores para evitar constante mobilização dos socioeducandos e fragilizar a segurança.

É necessário pontuar que a lógica da equivalência só é possível através de um processo que estabelece um conjunto de demandas que causam insatisfações, compartilhando-as em rede. Isso acontece no exterior (constitutivo) do discurso que é "incomensurável com o interior e, ao mesmo tempo, é condição para o seu surgimento" (MOUFFE, 2003, p. 29).

Através da lógica da equivalência o debate político, através da rede de significação discursiva, deu origem a uma política de currículo com diretrizes que buscam fixar uma identidade de sujeito, com a qual tenta operar na formação da identidade do socioeducando, de forma que através da educação integral formem adolescentes e jovens cidadãos autônomos, "[...] solidários e competentes que possam construir/resgatar sua cidadania e atuar produtivamente na sociedade e no mercado de trabalho" (PARAÍBA, 2017, p. 12). Isso gera regimes de verdade que entendem que tais sujeitos não possuem seus projetos de vida, bem como não são protagonistas, quando chegam às unidades socioeducativas, por serem autores de atos infracionais, o que é uma falácia.

A fixação de uma identidade e a construção de uma política de currículo para a produção dessa identidade como fruto de um discurso hegemônico que disputa com outros que o contestam, fazem parte de um processo de recontextualização por hibridismo como mecanismo que

[...] nos permite vislumbrar novas perspectivas de análise para a compreensão dos processos de reconhecimento, de legitimação, de interpretação e de apropriação das políticas curriculares nas diferentes instâncias pelas quais transitam até à sua efetiva implementação 
na instância da prática. É preciso considerar, entretanto, que sua utilização oferece oportunidades, riscos, ambivalências e possibilidades (MATOS; PAIVA, 2007, p. 187).

Nos termos de Laclau e Mouffe (2015), o movimento constante de sentido causado pelo processo de recontextualização por hibridismo não tem arena, lócus, nem atores privilegiados, não sendo estancados por determinação. Os sentidos são produzidos pela indeterminação das interpretações, cabendo à política de currículo, enquanto rede de significações discursivas, limitar as possibilidades. Essa instabilidade é o que causa a possibilidade de desagrupamento dos pontos nodais. O social é constituído pela linguagem e o discurso é toda objetividade.

Quanto aos agentes/sujeitos/atores eles têm ocupado a centralidade na teoria do discurso e nos estudos de Stephen Ball e, para nós, essa é a razão primeira para partirmos dessas teorizações, para inaugurarmos uma teorização para o campo do currículo que tivesse a mesma preocupação. Para Laclau e Mouffe (2015), o surgimento do agente político se dá nos momentos de decisão, o que Laclau (2000) chamaria de "momento do sujeito". Este momento é marcado pela capacidade do agente de incorporar à ordem simbólica através das identificações, produzindo-se como subjetividade concreta. Portanto, ele é o elemento que apresenta soluções para a crise da estrutura, que, através de um processo político, rearticula as demandas e resolve a crise.

É impreterível compreender que a política curricular de Educação Integral para adolescentes e jovens em cumprimento de medida socioeducativa, como rede de significação discursiva, busca estabelecer limites aos sentidos de educação, qualidade, identidade, tempo escolar, função social da escola no sistema socioeducativo e violência, através dessa subjetividade concreta, como possibilidade de solução para a crise a qual ela se prontifica a resolver. Essas afirmações nos fazem considerar a necessidade de nos deslocarmos ao contexto da prática, que ficará para textos posteriores, visto o limite gráfico estabelecido, mas que não abandonaremos por nos ajudarem a irmos construindo a perspectiva teórica curricular que operamos neste texto.

\section{ALGUMAS CONSIDERAÇÕES}

Nesta seção tecemos algumas considerações, mas não encerramos o diálogo, uma vez que estamos no processo de construção de uma perspectiva teórico-metodológica para os estudos sobre políticas curriculares. Também, não podemos finalizar as discussões sobre a política curricular do programa de Educação Integral para adolescentes e jovens que cumprem medida socioeducativa em privação de liberdade, não só pela escassez de pesquisas na área das políticas curriculares, mas também por um posicionamento político de contribuir para a reflexão e defesa do acesso desses 
adolescentes e jovens à educação de qualidade social, bem como condições de permanência e promoção.

Ao pensar a política curricular como rede de significação discursiva, identificamos que o agente político responsável por limitar o processo de produção de sentidos em um espaço antagônico e precário como o social foi o Governo do Estado da Paraíba, que buscou respostas para as insatisfações comuns com a educação no sistema socioeducativo.

Outro ponto importante para nossos estudos foi considerar a rede como constructo discursivo que estabelece agrupamentos por meio dos pontos nodais, que são demandas de insatisfações comuns que vão desenhando um tecido conectivo por onde os discursos transitam. Em dados momentos os agrupamentos nos pontos nodais se tornam tão grandes que hegemonizaram o discurso através da lógica da equivalência, sem perder em suas origens as diferenças que os constituem como outro, ou seja, o discurso hegemônico não pressupõe aqui uma uniformidade ou apagamento das demandas distintas, mas uma trégua momentânea em detrimento de algo mais urgente a essas diferenças, por isso a hegemonia é algo precário e cíclico.

Só através desse movimento fomos capazes de compreender que o processo de mobilidade da política curricular acontece justamente nos momentos em que a lógica da equivalência opera através de ferramentas dos diversos grupos que ela aglutina dentro de um dado discurso; nesse momento mobilidades são feitas em busca de resolver a insatisfação em comum.

Outro ponto interessante que precisamos considerar é que essa mobilidade através da equivalência desperta um outro movimento através da diferença que é a recontextualização, momento em que os grupos que recebem as políticas de outros locais/tempos/espaços a inserem num discurso local através da ordem simbólica própria, o que gera uma política híbrida. Esses processos nos fazem considerar que a política na rede passa por tantas arenas que as transforma em outras políticas que amenizam as marcas da ordem simbólica que lhes deram origem.

Percebemos, então, nessa fase inicial de análise da política, que existe um estereótipo das identidades dos meninos e meninas que cumprem medida socioeducativa, mas enxergamos uma compreensão, que as relações e sentidos que esses dão ao ato infracional, estão relacionados com a negação de direitos fundamentais, tais como: educação, saúde, moradia, alimentação, entre outros.

\section{REFERÊNCIAS}

BALL, S. J. Educação global S. A.: novas redes políticas e o imaginário neoliberal. Ponta Grossa: Editora da UEPG, 2014. 
Education Reform: a critical an post-structural approach. Philadelphia: Open University Press, 1994.

. Global education Inc.: new policy networks and the neoliberal imaginary. New York: Routledge, 2012.

BALL, S. J.; JUNEMANN, C. Networks, new governance and education. Bristol: The Policy Press, 2012.

BOWE, R.; BALL, S. J.; GOLD, A. Reforming Education and Changing Schools: Case Studies in Policy Sociology. London: Routledge, 1992.

BRASIL. Decreto n ${ }^{\circ}$ 37.505, de 18 de julho de 2017. Cria o Programa de Educação Cidadã Integral para o Atendimento de Jovens em Cumprimento de Medidas Socioeducativas - Janela para o Futuro. Diário Oficial, n. 16.415, Paraíba, pp. 11,19 jul. 2017.

. Resolução CNE/CEB $n^{\circ}$ 3, de 13 de maio de 2016. Define Diretrizes Nacionais para o atendimento escolar de adolescentes e jovens em cumprimento de medidas socioeducativas, 2016. Disponível em: <http://portal.mec.gov.br/index.php?option=com_docman\&view=download\&alias=41061-rceb003-16-

pdf\&category_slug=maio-2016-pdf\&Itemid=30192>. Acesso em: 02 mar. 2017.

ICE - Instituto de Corresponsabilidade pela Educação. Livro institucional. 2016. Disponível em: <http://icebrasil.org.br/sobre-o-ice/>. Acesso em: 06 maio 2019.

LACLAU, E. A razão populista. Tradução: Carlos Eugênio Marcondes de Moura. São Paulo: Três Estrelas. 2013. Emancipação e diferença. Rio de Janeiro: EdUERJ, 2011.

Económica, 2000.

Misticismo, retórica y política. Buenos Aires: Fondo de Cultura

. New Reflections on the Revolution of Our Time. London, Verso, 1990.

LACLAU, E.; MOUFFE, C. Hegemonia e estratégia socialista: por uma política democrática radical. Tradução: Joanildo A. Burity, Josias de Paula Jr e Aécio Amaral. São Paulo: Instermeios, Brasilia: CNPq, 2015.

LOPES, A. C. Discursos nas políticas de currículo. Currículo sem Fronteiras, v. 6, n. 2, p. 33-52, jul./dez. 2006.

. Normatividade e intervenção política: em defesa de um investimento radical. In: LOPES, A. C.; MENDONÇA, Daniel de (org.). A teoria do discurso de Ernesto Laclau: ensaios críticos e entrevistas. São Paulo: Annablume, 2015 b. p. 117-147. v. 1 .

LOPES, A. C.; DIAS, R. E.; ABREU, R. G. Discursos nas políticas de currículo. Rio de Janeiro: Quartet, 2012.

LOPES, A. C.; OLIVEIRA, A. L. A R. M.; OLIVEIRA, G. G. S. A teoria do discurso na pesquisa em educação. Recife: Ed. UFPE, 2018.

MACEDO, E. As demandas conservadoras do Movimento Escola Sem Partido e a Base Nacional Curricular Comum. Educ. Soc., Campinas, v. 38, n. 139, p. 507-524, abr./jun. 2017.

. Base nacional curricular comum: novas formas de sociabilidade produzindo sentidos para educação. Revista Ecurriculum, v. 12, n. 4, p. 1530-1556, 2014.

2016.

Por uma leitura topológica das políticas curriculares. Archivos Analíticos de Políticas Educativas, v. 24, n. 26,

. Repolitizar o social e tomar de volta a liberdade. Educ. rev. [online], v. 34, e212010, 2018.

MACEDO, E.; LOPES, A. Reconfigurações nos estudos sobre políticas de currículo. Currículo sem Fronteiras, v. 6, n. 2, p. 5-9, 2006. 
MACEDO NETO, Manoel Pereira. Análise das relações entre o universal e o particular no currículo e no ensino de História: um diálogo com a Teoria do Discurso de Ernesto Laclau e Chantal Mouffe. Anais do XVI Encontro Estadual de História. v. 16, n. 1. Campina Grande, ago. 2014.

. Leituras pós-estruturalistas e discursivas do currículo-ensino de História: uma análise das tensões e negociações entre referenciais curriculares nacionais, documentos locais e o mundo da escola. Anais do XXVIII Simpósio Nacional de História. v. 18, n. 1. Florianópolis, jul. 2015.

MAIA, A. A. M. Educação para a cidadania no ensino médio: uma aproximação das articulações discursivas de alunos, docentes e documentos curriculares no âmbito da sociologia. 2014. Tese (Doutorado) - Programa de Pós-graduação em Educação da Universidade Federal da Paraíba, João Pessoa, 2014.

MATOS, M. C. M.; PAIVA, E. V. Hibridismo e currículo: ambivalências e possibilidades. Currículo sem Fronteiras, v. 7, n. 2, p. 185-201, jul./dez. 2007.

MOUFFE, C. Democracia, cidadania e a questão do pluralismo. Política \& Sociedade, Florianópolis, v. 1, n. 3, p. 11-26, out. 2003.

PARAÍBA. Decreto n ${ }^{\circ}$ 37.505, de 18 de julho de 2017, Cria o Programa de Educação Cidadã Integral para o Atendimento de Jovens em Cumprimento de Medidas Socioeducativas - Janela para o Futuro. Diário Oficial $n^{\circ} 16.415$, Paraíba, PB, p. 11, 19 jul. 2017.

. Plano Estadual de Atendimento Socioeducativo da Paraíba (2015-2024). João Pessoa: Secretaria de Estado e Desenvolvimento Humano (SEDH), 2015

PEREIRA, M. Z. C. A centralidade da pluralidade cultural nos debates contemporâneos no campo do currículo. Currículo sem Fronteiras, v. 9, n. 2, p. 169-184, jul./dez. 2009a.

. Currículo, discurso e discursos. In: MACEDO, Elizabeth; Roberto Sidnei Macedo; AMORIM, Antônio Carlos (org.). Discurso, texto, narrativa nas pesquisas em currículo. Campinas - SP: FE/UNICAMP, 2009b. p. 114-123.

PEREIRA, Maria Zuleide Costa et al. (org.). Diferenças nas políticas de currículo. João Pessoa: Editora Universitária da UFPB, 2010.

PEREIRA, M. Z. C.; ALBINO, A. C. A.; MAIA, A. A. M. M. Currículo como redes discursivas: aproximações com as vertentes pós-estruturalistas. In: FERRAÇO, Carlos Eduardo; GABRIEL, Carmen Teresa; AMORIM, Antônio Carlos (org.). Teoria e o Campo do Currículo. 1. ed. São Paulo: FE/UNICAMP, 2012. p. 31-42. v. 1. 


\title{
EDUCAÇÃO INTEGRAL NO SISTEMA SOCIOEDUCATIVO: O CURRÍCULO COMO REDES DE SIGNIFICAÇÕES DISCURSIVAS
}

Resumo: $\mathrm{O}$ artigo analisa as redes de significações discursivas presentes na organização curricular da Educação Integral para Jovens em Cumprimento de Medidas Socioeducativas em Privação de Liberdade do estado da Paraíba. Os procedimentos metodológicos centraram-se nas análises documentais e entrevistas semiestruturadas. Para as análises dos achados da pesquisa utilizamos a Teoria do Discurso de Laclau (2011, 2013) e Laclau e Mouffe (2015). Nas considerações destacamos que a política investigada vem estabelecendo padrões e compromissos para o sistema Socioeducativo, a partir do movimento de mobilidade e (re)contextualização que gerou currículos híbridos. Ressaltamos que o objetivo da política foi apresentar resultados rápidos quanto à redução da violência nos espaços sociais onde estavam inseridas as escolas.

Palavras-chave: Currículo. Socioeducação. Educação Integral.

\section{INTEGRAL EDUCATION IN THE SOCIO-EDUCATIONAL SYSTEM: THE CURRICULUM AS NETWORKS OF DISCURSIVE MEANINGS}

\begin{abstract}
The article analyzes the networks of discursive meanings present in the curricular organization of Integral Education for Young People in Compliance with Socio-Educational Measures in Deprivation of Freedom of the state of Paraíba. Methodological procedures focused on documentary analysis and semi-structured interviews. For the analysis of the research findings we used Laclau's Discourse Theory $(2011,2013)$ and Laclau and Mouffe (2015). In the considerations we highlight that the investigated policy has been establishing standards and compromises for the Socio-educational system, from the mobility and (re) contextualization movement that generated hybrid curricula. We emphasize that the objective of the policy was to present quick results regarding the reduction of violence in the social spaces where schools were inserted.
\end{abstract}

Keywords: Curriculum. Socio-education. Integral education.

\section{EDUCACIÓN INTEGRAL EN EL SISTEMA SOCIOEDUCATIVO: EL CURRÍCULO COMO REDES DE SIGNIFICADOS DISCURSIVOS}

\begin{abstract}
Resumen: El artículo analiza las redes de significados discursivos presentes en la organización curricular de Educación Integral para Jóvenes en Cumplimiento de Medidas Socioeducativas en Privación de Libertad del estado de Paraíba. Procedimientos metodológicos enfocados al análisis documental y entrevistas semiestructuradas. Para el análisis de los resultados de la investigación, utilizamos la teoría del discurso de Laclau $(2011,2013)$ y Laclau y Moyffe (2015). En las consideraciones destacamos que la política investigada ha estado estableciendo estándares y compromisos para el sistema Socioeducativo, desde el movimiento de movilidad y (re) contextualización que generó un currículum híbrido. Destacamos que el objetivo de la política era presentar resultados rápidos con respecto a la reducción de la violencia en los espacios sociales donde se insertaron las escuelas.
\end{abstract}

Palabras clave: Currículum. Socioeducación. Educación integral.

Submetido em Agosto de 2019

Aprovado em Dezembro de 2019

Revista Teias v. 20 • n. 59 • out/dez 2019 • Outras epistemologias e metodologias nas investigações sobre currículo 218 